Original Research Paper

\title{
Optimization of Cultural Conditions for Production of Exopolysaccaride by Halomonas marina HMA 103 under Batch-Culture
}

\author{
${ }^{1}$ Arundhati Pal, ${ }^{2}$ Amrita Biswas, ${ }^{2}$ Sriya Chatterjee and ${ }^{2}$ A.K. Paul \\ ${ }^{1}$ Department of Botany, Serampore College, \\ 9 William Carey Road, Serampore, Hooghly 712201, West Bengal, India \\ ${ }^{2}$ Department of Botany, Microbiology Laboratory, \\ University of Calcutta, 35, Ballygunge Circular Road, Kolkata 700 019, West Bengal, India
}

Article history

Received: 26-02-2015

Revised: $15-06-2015$

Accepted: 14-07-2015

Corresponding Author:

A.K. Paul

Department of Botany, Microbiology Laboratory,

University of Calcutta, 35,

Ballygunge Circular Road,

Kolkata 700 019, West Bengal, India

Email: amalk_paul@yahoo.co.in

\begin{abstract}
A moderately halophilic bacterium, Halomonas marina HMA 103 (MTCC 8968) accumulating intracellular polyesters also produced significant amount of exopolysaccharides (EPS) under batch-culture. Production of EPS by the bacterium was more or less parallel with the growth in modified basal synthetic medium. During growth, it produced $0.46 \mathrm{~g} / \mathrm{L}$ of EPS after $50 \mathrm{~h}$ of incubation and was accompanied by the complete utilization of glucose from the medium. EPS production was maximum in $2 \%(\mathrm{w} / \mathrm{v})$ glucose followed by sucrose and maltose and was positively influenced by yeast extract, beef extract and peptone. Optimum concentrations of sulfate and phosphate for EPS production were 2.4\% $(\mathrm{w} / \mathrm{v})$ and $0.03 \%(\mathrm{w} / \mathrm{v})$ respectively. High concentration $(10 \% \mathrm{w} / \mathrm{v})$ of $\mathrm{NaCl}$ stimulated both growth and EPS production by $H$. marina HMA 103. Characteristically, this EPS is a heteropolymer of glucose and mannose and the Fourier Transform Infrared (FTIR) spectrum showed distinct absorption peaks at $3424.2,1638.7,1122.9$ and $622.3 \mathrm{~cm}^{-1}$ indicating the presence of free hydroxyl, phenyl or carbonyl groups of carbohydrate. Further, the detailed physico-chemical analysis will indicate the significance and potential importance of this EPS in biotechnology.
\end{abstract}

Keywords: Halomonas, Moderately Halophilic Bacteria, Exopolysaccharides, Solar Saltern, Batch-Culture

\section{Introduction}

Moderately halophilic bacteria that require $3-15 \%$ $\mathrm{NaCl}$ for satisfactory growth (Kushner, 1988) are widely distributed throughout the hypersaline environment and have been recognized as valuable sources of new biomolecules including exopolysaccharides (Margesin and Schinner, 2001). These exopolysaccharides (EPS) play important role in the attachment of bacteria with substrates, development of biofilms, adsorption of nutrients, conservation of enzymes, defense against attack and protection against changes in physicochemical conditions (Wotton, 2004). In addition, EPS find applications in the field of pharmacy, food, cosmetics and petroleum industries (Sutherland, 2001; Flemming and Wingender, 2001).

Extensive search for EPS with novel properties have described several species of moderately halophilic bacteria belonging to the genus Halomonas. Two of them, Halomonas eurihalina (Bejar et al., 1998) and $H$. maura (Bouchotroch et al., 2001) have produced technologically viable quantities of extracellular polysaccharides with unique chemical composition and functional properties (Quesada et al., 2004). Amongst many others, novel species viz. H. ventosae (MartínezCánovas et al., 2004), H. anticariensis (MartinezCanovas et al., 2004) and H. almeriensis (MartinezCheca et al., 2005; Llamas et al., 2012) deserve special mention for synthesizing copious amounts of exopolysaccharides in culture.

Production of EPS by bacterial species in culture is greatly influenced by a number of factors, such as phases of growth, nutritional status and the environmental conditions. The nature and concentration of nutrients in particular, are necessary components for stimulation of growth and synthesis of EPS (Laws and Marshall, 2001; 
Pal and Paul, 2008). Further, the fermentation conditions play important role in determining the conformation, molecular mass, monosaccharide ratios and functional properties of the EPS (Sutherland, 1994; Finore et al., 2014). But until recently, there have been very few studies on the effect of nutrients and cultural conditions on the production and composition of EPS of moderately halophilic bacteria (Bouchotroch et al., 2000; Arias et al., 2003).

Halomonas marina HMA 103 (MTCC 8968), a moderately halophilic bacterium isolated in this laboratory from a hypersaline soil collected from solar salterns of coastal Odisha, India has been reported to produce significant amount biodegradable bioplastics, poly(3-hydroxybutyrate) and poly(3-hydroxybutyrateco-3-hydroxyvalerate) (Biswas et al., 2009). Along with accumulation of these intracellular polyesters, the isolate also produced substantial amount of exopolysaccharides. In this article, we report the influence of nutritional and environmental conditions for the production of exopolysaccharide by $H$. marina HMA 103 under batchculture experiments.

\section{Materials and Methods}

\section{Bacterial Strain and Cultural Conditions}

Moderatly halophilic bacterium, H. marina HMA 103 (MTCC 8968) previously isolated from multi-pond solar salterns of Odisha, India (Biswas et al., 2009) was used throughout the present study. The strain was maintained on Ventosa's agar medium (Ventosa et al., 1998) by regular subculturing at an interval of 30 days. The medium contained $(\mathrm{g} / \mathrm{L}): \mathrm{MgSO}_{4} .7 \mathrm{H}_{2} \mathrm{O}, 1.0$; $\mathrm{CaCl}_{2} .2 \mathrm{H}_{2} \mathrm{O}, 0.36 ; \mathrm{KCl}, 2.0 ; \mathrm{NaHCO}_{3}, 0.06 ; \mathrm{NaBr}, 0.23$; $\mathrm{FeCl}_{3}$, 0.005; peptone, 5.0; yeast extract,10.0; glucose, 1.0 and $\mathrm{NaCl}, 100.0$ (pH 7.2).

\section{Growth and Production of Exopolysaccharide}

Modified basal synthetic medium (Lillo and Rodriguez-Valera, 1990) which contained (g/L) $\mathrm{NH}_{4} \mathrm{Cl}$, 1.0; $\quad \mathrm{KH}_{2} \mathrm{PO}_{4}, \quad 0.3 ; \quad \mathrm{FeCl}_{3}, \quad 0.005 ; \mathrm{NaCl}, 100.0$; $\mathrm{MgCl}_{2} .6 \mathrm{H}_{2} \mathrm{O}, 16.0 ; \mathrm{MgSO}_{4} \cdot 7 \mathrm{H}_{2} \mathrm{O}, 24.0 ; \mathrm{CaCl}_{2} \cdot 2 \mathrm{H}_{2} \mathrm{O}$, $1.0 ; \mathrm{KCl}, 5.0 ; \mathrm{NaHCO}_{3}, 0.2 ; \mathrm{NaBr}, 0.5 ;$ glucose, 10.0 and yeast extract, $1.0(\mathrm{pH} 7.2)$ was used for growth and EPS production. The medium $(20 \mathrm{~mL} / 100 \mathrm{~mL}$ Erlenmeyer flask) was inoculated with $1.0 \mathrm{~mL}$ of freshly prepared inoculum in Ventosa's medium and incubated at $30^{\circ} \mathrm{C}$ on rotary shaker $(120 \mathrm{rpm})$. Growth was determined by measuring cell dry weight at regular interval. The cell mass was harvested by centrifugation $\left(10,000 \mathrm{xg}, 10 \mathrm{~min}, 20^{\circ} \mathrm{C}\right)$, washed twice with normal saline, cell pellet transferred to pre-weighed aluminum cups and dried to constant weight at $80^{\circ} \mathrm{C}$. The supernatant was cooled to $4^{\circ} \mathrm{C}$ and the soluble EPS was precipitated with double volume pre-chilled acetone, kept overnight at $4^{\circ} \mathrm{C}$ and recovered by centrifugation $\left(12,000 \mathrm{xg}, 4^{\circ} \mathrm{C}\right.$, for $\left.20 \mathrm{~min}\right)$. The cell bound EPS was extracted with 2\% EDTA and precipitated with chilled acetone as usual. The soluble and bound EPS were pooled and dissolved in known volume of distilled water prior to quantification.

\section{Purification of Exopolysaccharide}

The pooled EPS dissolved in distilled water was subjected to dialysis in sterile water for $72 \mathrm{~h}$ at $4^{\circ} \mathrm{C}$ with regular change of dialysate. On completion of dialysis, the EPS was again treated with chilled acetone at $4{ }^{\circ} \mathrm{C}$, the precipitate was collected by centrifugation $(12,000 \mathrm{xg}$, $4^{\circ} \mathrm{C}, 20 \mathrm{~min}$.) as the partially purified EPS and lyophilized at $-56^{\circ} \mathrm{C}$ to obtain white powdered polymer.

\section{Estimation of Exopolysaccharide}

EPS estimation was carried out following the phenolsulphuric acid method (Dubois et al., 1956) using glucose as the standard. EPS obtained from $1.0 \mathrm{~mL}$ of fermented broth was dissolved in $1.0 \mathrm{~mL}$ of distilled water. To this $1.0 \mathrm{~mL}$ of $5 \%(\mathrm{w} / \mathrm{v})$ phenol was added, mixed thoroughly and incubated for $5 \mathrm{~min}$. Following this, concentrated sulphuric acid $(5.0 \mathrm{~mL})$ was purged in using adjustable repeater pipette (Socorex Stepper TM 411), mixed immediately and incubated at $30^{\circ} \mathrm{C}$ for 10 min. Optical density of the reaction mixture was measured at $490 \mathrm{~nm}$ using Systronics colorimeter.

\section{Transmission Electron Microscopy Studies}

Cells from actively growing culture were stained with freshly prepared 2\% uranyl acetate and observed under Philips Transmission Electron Microscope (FEI Tecnai 12 BioTwin).

\section{Analysis of EPS}

The partially purified EPS was analyzed for its sugar, protein, uronic acid and nucleic acid contents. Total sugar content was estimated following the phenol-sulphuric acid method of Dubois et al. (1956) using glucose as standard. Estimation of sugar monomers was achieved by gas chromatography (Shimadzu GC-17A, Japan) following methanolysis of EPS. Protein content of EPS was estimated by folin-phenol reagent using bovine serum albumin as standard (Lowry et al., 1951). Nucleic acid was estimated by measuring the absorbance at $260 \mathrm{~nm}$ (Jenway UV-Vis spectrophotometer) using purified DNA as standard. Quantitative estimation of the uronic acids was spectrophotometrically performed following the method of Blumenkrantz and Asboe-Hansen (1973).

\section{Fourier Transform Infrared Spectroscopic Analysis}

The Fourier-Transform Infrared (FTIR) spectrum of the partially purified EPS was recorded in a Perkin 
Elmer RX-1 FTIR spectrometer. The purified sample after lyophilization at $-56^{\circ} \mathrm{C}$ was prepared as $\mathrm{KBr}$ pellet and scanned in the range of 500 to $4000 \mathrm{~cm}^{-1}$.

\section{Statistical Analysis}

All experiments were performed in triplicates and the results represent mean \pm standard error.

\section{Results}

\section{Growth Associated Exopolysaccharide Production}

Halomonas marina HMA 103 (MTCC 8968), the moderately halophilic heterotrophic bacterium previously isolated from solar slatterns of Odisha, India produced characteristic opaque, slimy colonies with profound accumulation of extracellular polysaccharides (EPS) when grown on Ventosa's agar medium containing 5 to $10 \% \mathrm{NaCl}$. Negatively stained cells of $H$. marina HMA 103 showed distinct accumulation of EPS from the early stages of growth (Fig. 1), which remain loosely adhered to the cells and was easily extracted with $2 \%(\mathrm{w} / \mathrm{v})$ EDTA. During growth under shake flask condition in modified basal synthetic medium (Lillo and Valera, 1990), the extracellular polymer accumulation was found to be more or less parallel with the growth of the bacterium and the highest EPS production $(0.46 \mathrm{~g} / \mathrm{L})$ was obtained during the late stationary phase (Fig. 2). Production of EPS was accompanied by gradual utilization of glucose and decline of $\mathrm{pH}$ of the medium (final $\mathrm{pH} 5.0,55 \mathrm{~h}$ ).

\section{Optimization of Cultural Conditions for EPS Production}

Growth and production of extracellular polysaccharide by $H$. marina HMA 103 was influenced by the presence different carbon sources like glucose, sucrose, fructose, maltose, acetate, citrate and malonate in the medium. Although, acetate followed by citrate appeared to be most suitable for growth of the bacterium, maximum exopolysaccharide production was detected in presence of glucose followed by sucrose and maltose (Table 1). Variation in the concentration of glucose in the fermentation medium clearly indicated that polymer production by H. marina HMA 103 was more or less parallel with the growth accounting maximum EPS production $(0.69 \mathrm{~g} / \mathrm{L})$ at $2 \%(\mathrm{w} / \mathrm{v})$ glucose (Fig. 3).

Supplementation of both inorganic and organic nitrogenous substances in the growth medium at $0.1 \%$ $(\mathrm{w} / \mathrm{v})$ level showed discrete variation in the growth and polymer production by the isolate HMA 103. Amongst the nitrogenous sources, yeast extract, peptone, beef extract and ammonium chloride enhanced the polymer production significantly $(0.47 \mathrm{~g} / \mathrm{L}$ to $0.50 \mathrm{~g} / \mathrm{L})$ (Table 2$)$.
Table 1. Effect of different carbon sources on growth and exopolysaccharide production by H. marina HMA 103

\begin{tabular}{llll}
\hline $\begin{array}{l}\text { Carbon source } \\
1 \%(w / v)\end{array}$ & $\begin{array}{l}\text { Growth } \\
(\mathrm{CDW} g / \mathrm{L})\end{array}$ & $\begin{array}{l}\text { EPS yield } \\
(\mathrm{g} / \mathrm{L})\end{array}$ & $\begin{array}{l}\text { Final } \mathrm{pH} \\
\text { of the medium }\end{array}$ \\
\hline Glucose (control) & $4.25 \pm 0.01$ & $0.46 \pm 0.01$ & 5.05 \\
Sucrose & $3.75 \pm 0.01$ & $0.34 \pm 0.02$ & 5.03 \\
Fructose & $1.18 \pm 0.01$ & $0.22 \pm 0.01$ & 6.70 \\
Maltose & $3.5 \pm 0.01$ & $0.33 \pm 0.01$ & 5.81 \\
Sodium acetate & $5.5 \pm 0.01$ & $0.18 \pm 0.01$ & 8.68 \\
Sodium citrate & $5.35 \pm 0.01$ & $0.23 \pm 0.01$ & 8.78 \\
Sodium malonate & $2.75 \pm 0.01$ & $0.04 \pm 0.02$ & 8.38
\end{tabular}

CDW $=$ Cell Dry Weight, EPS = Exopolysaccharides

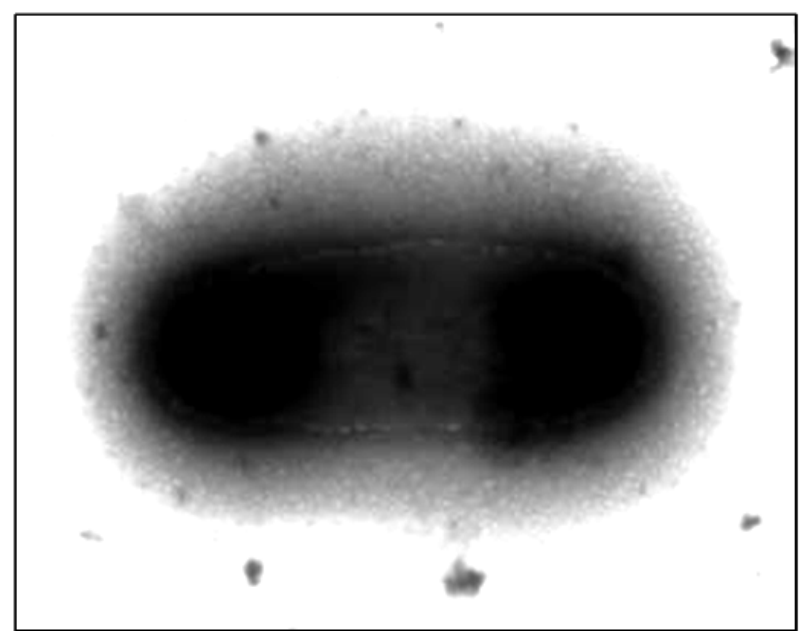

Fig. 1. Transmission electron micrograph of negatively stained cell of H. marina HMA 103 displaying cell bound extracellular polysaccharides (EPS)

Growth and EPS production by HMA 103 increased with increasing concentration of ammonium chloride, highest growth and exopolysaccharide production being achieved at $0.1 \%(\mathrm{w} / \mathrm{v}) \mathrm{NH}_{4} \mathrm{Cl}$. However, in yeast extract, growth and EPS production exhibited a different relationship. While, maximum EPS production was recorded at $0.1 \%(\mathrm{w} / \mathrm{v})$ yeast extract, biomass formation increased steadily with increasing concentration $[0.2 \%(\mathrm{w} / \mathrm{v})]$ of yeast extract (Fig. $4 \mathrm{~A}$ and B).

The optimal concentrations for both growth and EPS production by $H$. marina HMA 103 were estimated to be $2.4 \%(\mathrm{w} / \mathrm{v})$ and $0.3 \%(\mathrm{w} / \mathrm{v})$ of sulphate (Fig. 5A) and phosphate ((Fig. 5B) respectively. Increasing concentrations of sulphate as well as phosphate retarded both biomass formation and extracellular polymer production.

Halomonas HMA 103 showed a wide degree of tolerance to sodium chloride $(25 \% \mathrm{w} / \mathrm{v})$ in the growth medium. Growth and EPS production by the isolate followed a more or less parallel behavior with respect to $\mathrm{NaCl}$ concentration and maximum exopolymer yield $(0.42 \mathrm{~g} / \mathrm{L})$ was recorded at $10 \%$ (w/v) $\mathrm{NaCl}$ (Fig. 6). 

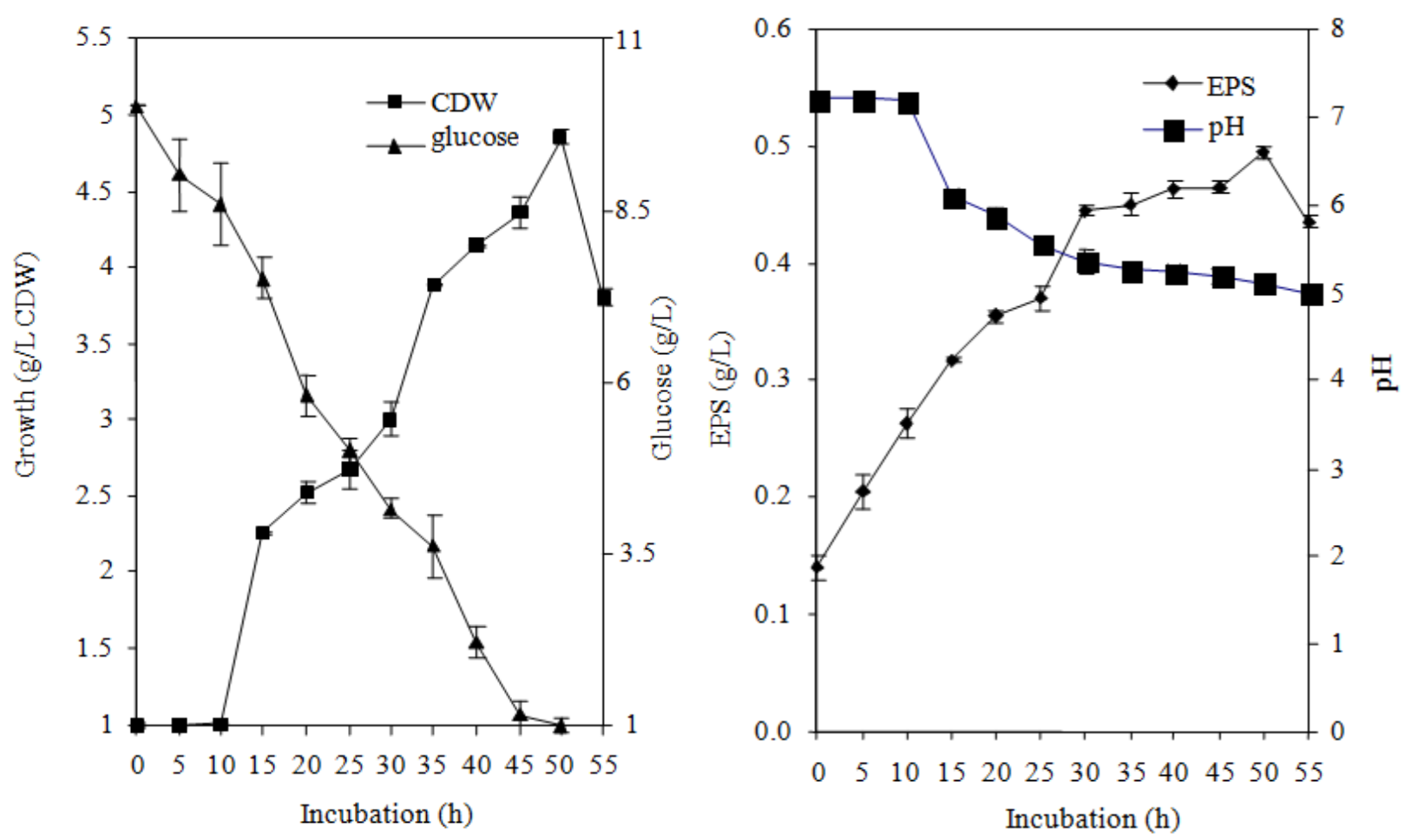

Fig. 2. Time course of growth and EPS production by H. marina HMA 103 in modified basal synthetic medium. Residual glucose concentration and final $\mathrm{pH}$ of the medium were also estimated. CDW $=$ Cell Dry Weight

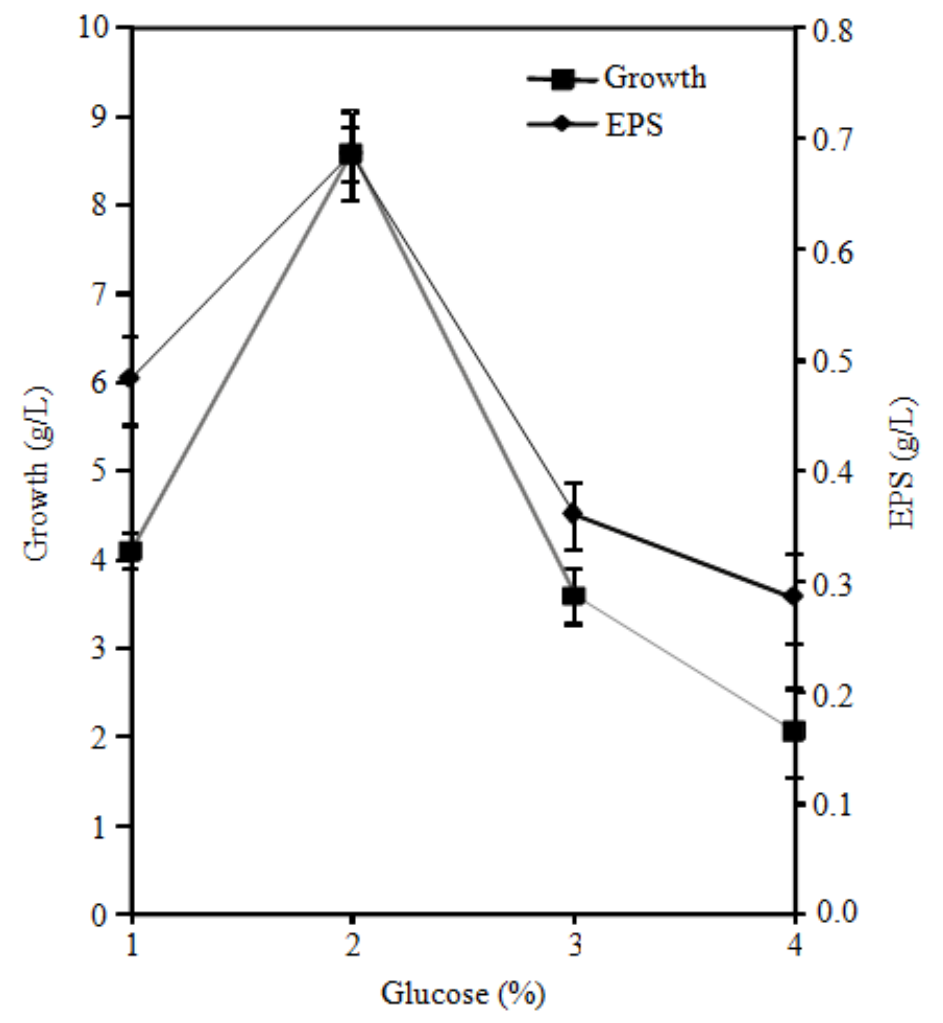

Fig. 3. Effect of increasing glucose concentration on growth and EPS production by H. marina HMA 103 


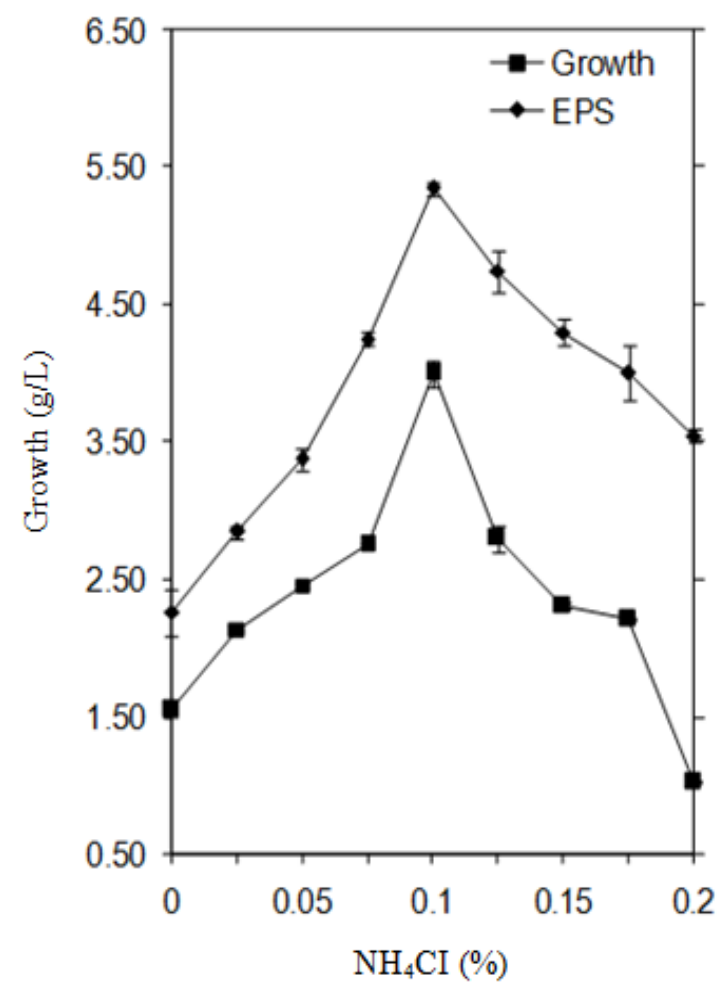

(A)

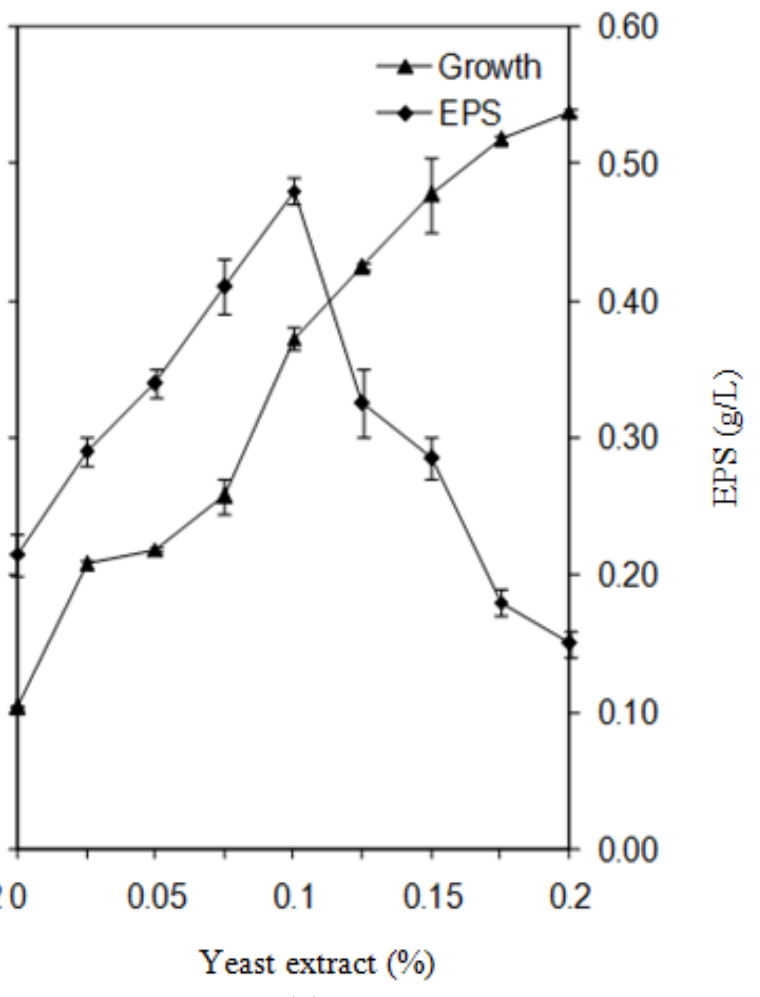

(B)

Fig. 4. Effect of increasing concentration of ammonium chloride (A) and yeast extract (B) on growth and EPS production by $H$. marina HMA 103

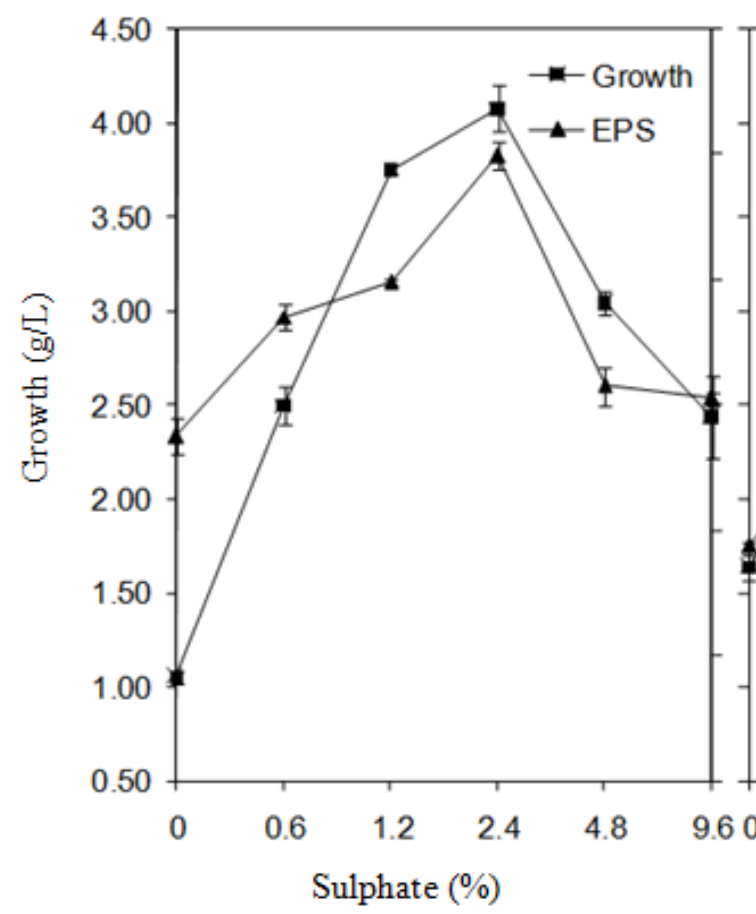

(A)

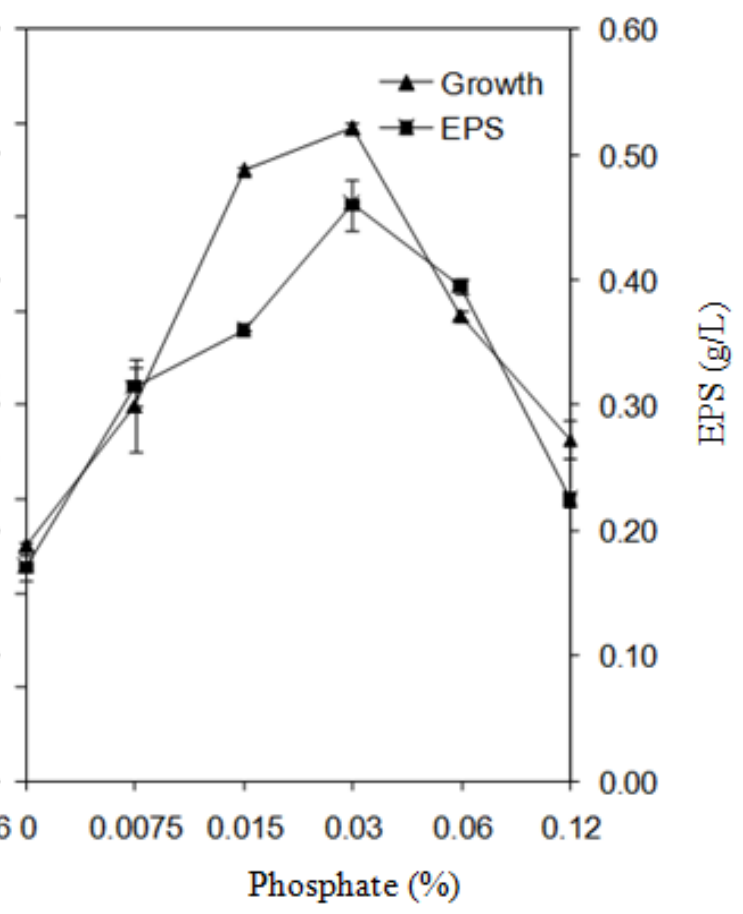

(B)

Fig. 5. Effect of sulphate (A) and phosphate (B) on growth and EPS production by H. marina HMA 103 


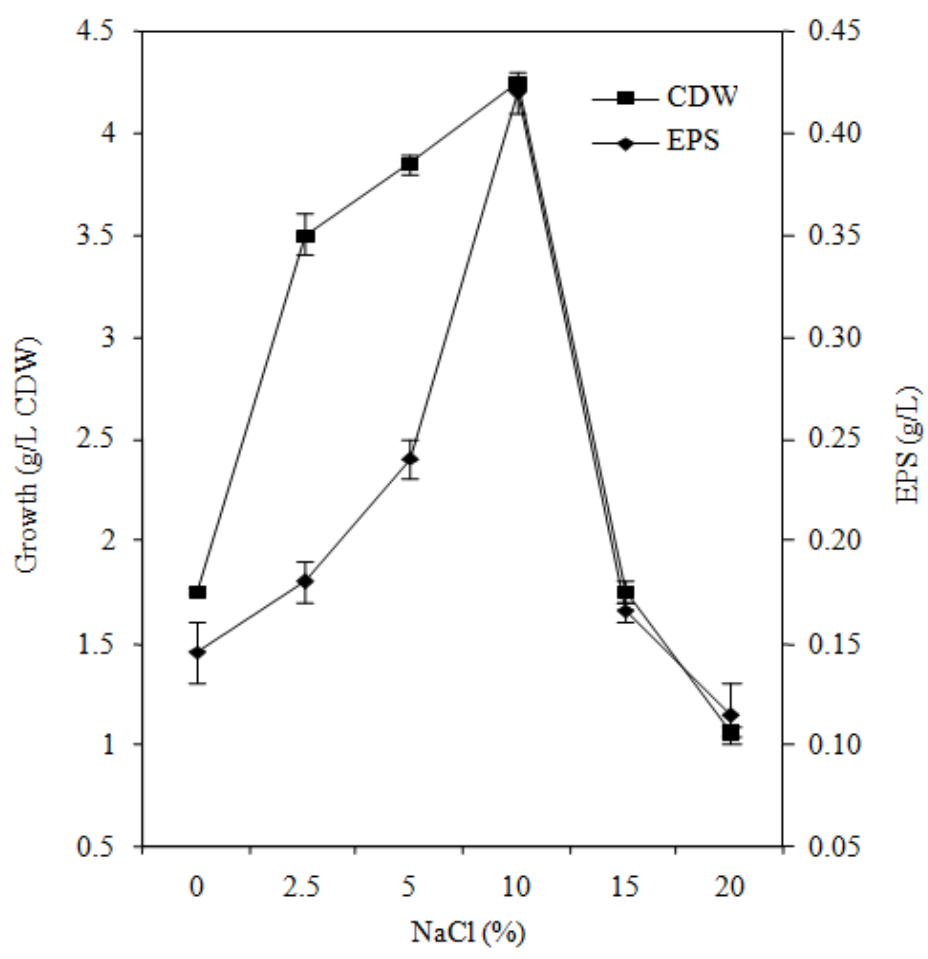

Fig. 6. Effect of increasing concentrations of sodium chloride on growth and EPS production by H. marina HMA 103

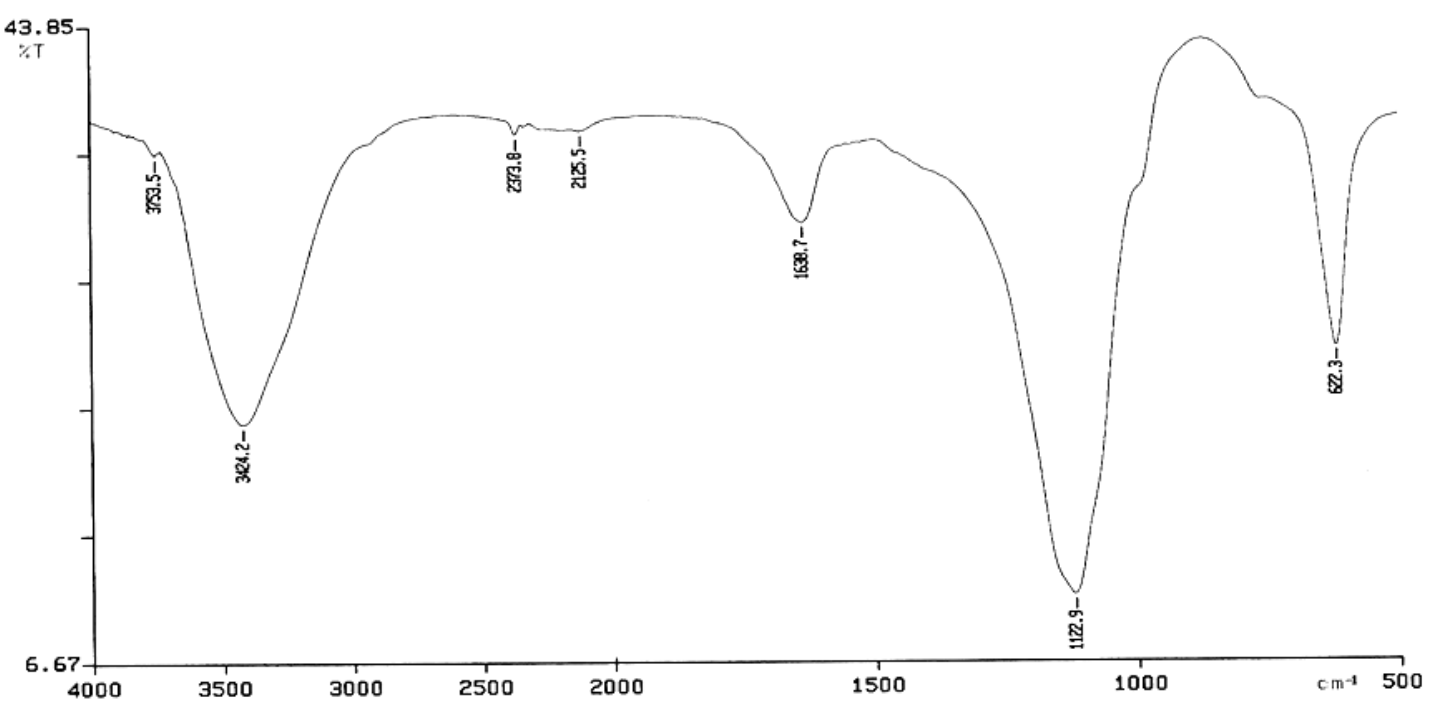

Fig. 7. Fourier transform infrared spectra of purified EPS produced by H. marina HMA 103. Purified EPS powder was prepared as $\mathrm{KBr}$ pellet and scanned in the range 4000 to $500 \mathrm{~cm}^{-1}$

\section{Characterization of EPS}

The purified EPS of Halomonas HMA 103 was subjected to compositional analysis and it was found to be a heteropolymer of glucose and mannose. Protein, nucleic acids and uronic acids were not detected. FTIR spectrum of purified exopolysaccharide prepared as $\mathrm{KBr}$ pellet is illustrated in Fig. 7. The spectrum shows characteristic absorption peaks at 3424.2, 1638.7, 1122.9 and $622.3 \mathrm{~cm}^{-1}$; along with few weak vibrations at $3753.5,2373.8$ and $2125.5 \mathrm{~cm}^{-1}$. The broad $\mathrm{O}-\mathrm{H}$ stretching vibration observed at $3424.2 \mathrm{~cm}^{-1}$ indicated presence of free hydroxyl groups of carbohydrates. The medium $\mathrm{C}=\mathrm{C}$ stretching vibration at $1638.7 \mathrm{~cm}^{-1}$ might indicate phenyl ring or presence of conjugated carbonyl groups. The strong stretching band at 1122.9 
$\mathrm{cm}^{-1}$ may be assigned to -COC- group indicating presence of cyclic structures of carbohydrates. The minor bands at 2373.8 and $2125.5 \mathrm{~cm}^{-1}$ might indicate presence of alkynes in the exopolysaccharide.

\section{Discussion}

Production of extracellular polysaccharide by moderately halophilic Halomonas spp. has long been recognized as a character of taxonomic significance (Mata et al., 2006) and commercial importance (Flemming and Wingender, 2001). The quality and quantity of EPS produced by an organism is greatly influenced by fermentation conditions and medium composition (Sutherland, 1998). We describe here the production of extracellular polysaccharide by $H$. marina HMA 103, part of which remain in cell-bound form (Fig. 1 ), while the rest is released into the growth medium as soluble EPS. Nutritional and cultural conditions have been optimized in the modified basal synthetic medium (Lillo and Rodriguez-Valera, 1990) under shake flask culture. The high yield of EPS accompanied by increasing cell mass formation indicated a balanced growth of Halomonas HMA 103 in synthetic medium until the glucose as sole source of carbon was consumed and caused cessation of EPS production (Fig. 2). Unlike many other organisms (Pham et al., 2000), there was no significant decrease in the quantity of EPS during the subsequent phases of incubation which indicated possible lack of EPS degradation and utilization in the culture.

The presence of a suitable carbon source providing energy for cellular growth is an essential requirement for the EPS production. The bacterium, HMA 103 grew and produced EPS in a variety of carbon sources, reflecting variations in the carbon source utilization pattern. The isolate preferred acetate and citrate for growth, while glucose was best utilized for polymer production (Table 1). However, glucose above the optimum concentration $(2 \% \mathrm{w} / \mathrm{v})$ impedes both growth and EPS production (Fig. 3). In haloalkalophilic Halomonas sp. CRSS, acetate was the most efficient carbon source producing a fructoglucan polysaccharide (Poli et al., 2004), while Halomonas sp. TG39 yielded a high molecular weight extracellular polymeric substance (HMW-EPS) when grown on glucose $(1 \% \mathrm{w} / \mathrm{v})$ and a peptone : yeast extract ratio of 5:1 (Gutierrez et al., 2009).

During the course of optimization of nitrogen sources, individual organic and inorganic nitrogen sources were supplemented in the basal medium. In comparison with inorganic nitrogen sources, organic nitrogenous compounds supported higher biomass and EPS production (Table 2). Production of EPS was triggered by lower concentrations of $\mathrm{NH}_{4} \mathrm{Cl}$ and yeast extract, however, the excess of organic and inorganic nitrogen appeared to be utilized for generating the biomass of H. marina HMA 103 (Fig. 4).
Table 2. Effect of different nitrogenous substances on growth and exopolysaccharide production by $H$. marina HMA 103

\begin{tabular}{llll}
\hline $\begin{array}{l}\text { Nitrogen } \\
\text { source }\end{array}$ & $\begin{array}{l}\text { Growth } \\
(\mathrm{CDW} g / \mathrm{L})\end{array}$ & $\begin{array}{l}\text { EPS } \\
(\mathrm{g} / \mathrm{L})\end{array}$ & $\begin{array}{l}\text { Final } \\
(\mathrm{pH})\end{array}$ \\
\hline Organic & & & \\
Yeast extract & $4.45 \pm 0.50$ & $0.50 \pm 0.01$ & 6.06 \\
Beef extract & $4.45 \pm 0.25$ & $0.47 \pm 0.01$ & 5.74 \\
Tryptone & $4.25 \pm 0.75$ & $0.43 \pm 0.01$ & 6.24 \\
Peptone & $4.00 \pm 0.10$ & $0.49 \pm 0.02$ & 6.35 \\
Casein hydrolysate & $4.00 \pm 0.01$ & $0.35 \pm 0.06$ & 6.39 \\
Inorganic & & & \\
Ammonium chloride & $4.15 \pm 0.01$ & $0.47 \pm 0.05$ & 5.33 \\
Ammonium sulphate & $4.00 \pm 0.01$ & $0.41 \pm 0.01$ & 5.57 \\
Ammonium nitrate & $3.25 \pm 0.25$ & $0.36 \pm 0.03$ & 5.49 \\
Potassium nitrate & $1.50 \pm 0.01$ & $0.10 \pm 0.01$ & 7.58 \\
\hline Nitrogen sources & &
\end{tabular}

Nitrogen sources were used at $0.1 \%(\mathrm{w} / \mathrm{v})$ level

Stressful culture condition in presence of excess carbon often enhances the production of EPS. Limiting phosphate ion concentrations in the growth medium appeared to be a triggering factor for enhanced production of EPS by the bacterial strain HMA 103 (Fig. 5B). However, sulfate at sub-optimal concentration failed to show any such induction (Fig. 5A). High $\mathrm{NaCl}$ concentrations $(10 \% \mathrm{w} / \mathrm{v})$ also resulted in more watersoluble EPS production by HMA 103 (Fig. 6), more or less identical to that of the photosynthetic bacterium, Rhodopseudomonas acidophila (Sheng et al., 2006).

The Fourier Transform Infrared spectroscopy has been used as a rapid and sensitive analytical technique for qualitative characterization of microbial cells and cell components like EPS (Sheng et al., 2006). The major peaks in the FTIR spectra (Fig. 7) of EPS obtained from Halomonas HMA 103 at 3424.2, 1122.9 and $622.3 \mathrm{~cm}^{-1}$ confirmed the presence of carbohydrates, while absence of vibrations at 2860,1660 and $1250 \mathrm{~cm}^{-1}$ confirmed the absence of proteins, uronic acids, nucleic acids and lipids (Sheng et al., 2006; Jiao et al., 2010), which also confirmed the data of the biochemical analysis of the EPS. Gas chromatography, on the other hand has confirmed the heteropolymeric nature of the EPS from HMA 103 being composed of glucose and mannose.

\section{Conclusion}

It is, therefore, apparent that the moderately halophilic bacterium $H$. marina HMA 103 is capable of producing considerable amount of exopolysaccharide utilizing an array of carbon and nitrogen sources under high saline conditions suggesting its implication in the production of the exopolymer under extreme saline environment. The organism thereby could be a potential source of biopolymer possessing unique properties for future biotechnological applications. However, an in-depth physico-chemical analysis of HMA 103 exopolysaccharide is essentially required to explore such potentials. 


\section{Author's Contributions}

All authors equally contributed to this work.

\section{Ethics}

The corresponding author confirms that all of the other authors have read and approved the manuscript and no ethical issues involved.

\section{References}

Arias, S., A. del Moral, M.R. Ferrer, R. Tallon and E. Quesada et al., 2003. Mauran, an exopolysaccharide produced by the halophilic bacterium Halomonas maura, with a novel composition and interesting properties for biotechnology. Extremophiles, 7: 319-326.

DOI: $10.1007 / \mathrm{s} 00792-003-0325-8$

Bejar, V., I. Llamas, C. Calvo and E. Quesada, 1998. Characterization of exopolysaccharides produced by 19 halophilic strains of the species Halomonas eurihalina. J. Biotechnol., 61: 135-141. DOI: 10.1016/S0168-1656(98)00024-8

Biswas, A., A. Patra and A.K. Paul, 2009. Production of poly-3-hydroxyalkanoic acids by a moderately halophilic bacterium, Halomonas marina HMA 103 isolated from solar saltern of Orissa, India. Acta Microbiol. Immunol. Hung., 56: 125-43.

DOI: 10.1556/AMicr.56.2009.2.9

Blumenkrantz, N. and G. Asboe-Hansen, 1973. New method for quantitative determination of uronic acids. Anal. Biochem., 54: 484-489.

DOI: 10.1016/0003-2697(73)90377-1

Bouchotroch, S., E. Quesada, A. Del Moral, I. Llamas and V. Bejar, 2001. Halomonas maura sp. nov., a novel moderately halophilic, exopolysaccharideproducing bacterium. Int. J. Syst. Evol. Microbiol., 51: 1625-1632. DOI: 10.1099/00207713-51-5-1625

Bouchotroch, S., E. Quesada, I. Izqueierdo, M. Rodriguez and V. Bejar, 2000. Bacterial exopolysaccharide produced by newly discovered bacteria belonging to the genus Halomonas, isolated from hypersaline habitats in Morocco. J. Ind. Microbiol. Biotechnol., 24: 374-378.

DOI: $10.1038 /$ sj.jim.7000002

Dubois, M., K.A. Gilles, J.K. Hamilton, P.A. Rebers and F. Smith, 1956. Colorimetric method for the determination of sugar and related substances. Anal. Chem., 28: 350-356. DOI: 10.1021/ac60111a017

Finore, I., P. Di Donato, V. Mastascusa, B. Nicolaus and A. Poli, 2014. Fermentation technologies for theoptimization of marine microbial exopolysaccharide production. Marine Drug, 12: 3005-3024.

DOI: $10.3390 / \mathrm{md} 12053005$
Flemming, H.C. and J. Wingender, 2001. Relevance of microbial Extracellular Polymeric Substances (EPSs)-Part I: Structural and ecological aspects. Water Sci. Technol., 43: 1-8.

Gutierrez, T., G. Morris and D.H. Green, 2009. Yield and physicochemical properties of EPS from Halomonas sp. strain TG39 identifies a role for protein and anionic residues (sulfate and phosphate) in emulsification of $\mathrm{n}$-hexadecane. Biotechnol. Bioeng., 103: 207-216. DOI: 10.1002/bit.22218

Jiao, Y., G.D. Cody, A.K. Harding, P. Wilmes and M. Schrenk et al., 2010. Characterization of extracellular polymeric substances from acidophilic microbial biofilms. Appl. Environ. Microbiol., 76: 2916-2922. DOI: 10.1128/AEM.02289-09

Kushner, D.J., 1988. What is the "true" intracellular salt concentration of halophilic bacteria? Can. J. Microbiol., 34: 482-486. DOI: 10.1139/m88-082

Laws, A.P. and V.M. Marshall, 2001. The relevance of exopolysaccharides to the rheological properties in milk fermented with ropy strains of lactic acid bacteria. Int. Dairy J. 11: 709-721.

DOI: 10.1016/S0958-6946(01)00115-7

Lillo, J.G. and F.R. Rodriguez-Valera, 1990. Effects of culture conditions on poly( $\beta$-hydroxybutyric acid) production0 by Haloferax mediterranei. Appl. Environ. Microbiol., 56: 2517-2521.

Llamas, I., H. Amjres, J.A. Mata, E. Quesada and V. Béjar, 2012. The potential biotechnological applications of the exopolysaccharide produced by the halophilic bacterium Halomonas almeriensis. Molecules, 17: 7103-7120.

DOI: $10.3390 /$ molecules 17067103

Lowry, O.H., N.J. Resebrough and A.L. Farr, 1951. Protein measurement with the folin-phenol reagent. J. Biol. Chem., 193: 265-275.

Mata, J.A., V. Béjar, I. Llamas, S. Arias, P. Bressollier, R. Tallon, M.C.Urdaci, E. Quesada, 2006. EPS produced by the recently described halophilic bacteria Halomonas ventosae and Halomonas anticariensis. Res. Microbiol., 157: 827-835.

DOI: 10.1016/j.resmic.2006.06.004.

Margesin, R. and F. Shinner, 2001. Potential of halotolerant and halophilic microorganisms for biotechnology. W. J. Microbiol. Technol., 11: 85-94. DOI: 10.1007/BF00339138

Martínez-Cánovas, M.J., E. Quesada, I. Llamas and V. Béjar, 2004. Halomonas ventosae sp. nov., a moderately halophilic, denitrifying, exopolysaccharide-producing bacterium. Int. J. Syst. Evol. Microbiol., 54: 733-737.

DOI: 10.1099/ijs.0.02942-0 
Martinez-Checa, F., V. Béjar, M.J. Martínez-Cánovas, I. Llamas and E. Quesada, 2005. Halomonas almeriensis sp. nov., a moderately halophilic, exopolysaccharide-producing bacterium from Cabo de Gata, Almería, south-east Spain. Int. J. Syst. Evol. Microbiol., 55: 2007-2011. DOI: 10.1099/ijs.0.63676-0

Pal, A. and A.K. Paul, 2008. Microbial extracellular polymeric substances: Central elements in heavy metal bioremediation. Indian J. Microbiol., 48: 49-64. DOI: $10.1007 / \mathrm{s} 12088-008-0006-5$

Pham, P.L., I. Dupont, D. Roy, G. Lapointe and J. Cerning, 2000. Production of exopolysaccharide by Lactobacillus rhamnosus $\mathrm{R}$ and analysis of its enzymatic degradation during prolonged fermentation. Appl. Environ. Microbiol., 66: 2302-2310.

DOI: 10.1128/AEM.66.6.2302-2310.2000

Poli, A., V.S. Moriello, E. Esposito, L. Lama and A. Gambacorta et al., 2004. Exopolysaccharide production by a new Halomonas strain CRSS isolated from saline Lake Cape Russell in Antarctica growing on complex and defined media. Biotechnol. Lett., 26: 1635-1638. DOI: 10.1007/s10529-004-3187-y
Quesada, E., V. Béjar, M.R. Ferrer, C. Calvo and I. Llamas et al., 2004. Moderately Halophilic Exopolysaccharide-Producing Bacteria. In: Halophilic Microorganisms, A. Ventosa (Ed.), Heidelberg, Springer, pp: 297-314.

Sheng, G.P., H.Q. Yu and Z. Yue, 2006. Factors influencing the production of extracellular polymeric substances by Rhodopseudomonas acidophila Int. Biodet. Biodeg., 58: 89-93. DOI: 10.1016/j.ibiod.2006.07.005

Sutherland, I.W., 1994. Structure-function relationships in microbial exopolysaccharides. Biotechnol. Adv., 12: 393-448. DOI: 10.1016/0734-9750(94)90018-3

Sutherland, I.W., 1998. Novel and established applications of microbial polysaccharides. Trends Biotechnol., 16: 41-46.

DOI: $10.1016 / \mathrm{S} 0167-7799(97) 01139-6$

Sutherland, I.W., 2001. Biofilm exopolysaccharides: A strong and sticky framework. Microbiology, 147: 3-9.

Ventosa, A., J.J. Nieto and A. Oren, 1998. Biology of aerobic moderately halophilic bacteria. Microbiol. Mol. Biol. Rev., 62: 504-544. DOI: $1092-2172 / 98 / \$ 04.00+0$

Wotton, R.S., 2004. The ubiquity and many roles of Exopolymers (EPS) in aquatic systems. Sci. Mar., 68: 13-21. DOI: 10.3989/scimar.2004.68s113 